\title{
Beyond the City Centre Car Parks: Lessons from the Developed Cities
}

\author{
S. N. Bentotage
}

Abstract : Although road pricing, time restrictions, priority bus lanes, and no car zones discourage the car usage in the city circles, construction of car parks never stop cars entering into cities and roaming for parking. Devoid of restrictions for car usage, many developed cities were compelled to employ hightech parking management to cope with ever increasing demand for parking. Without pursuing the same mistake, the developing cities can learn the sustainable solutions that have been suggested for the developed cities. Development of public transport as an alternative to everyone while restricting the car usage would be the best solution for a geographically constricted city with lot of archaeologically valuable sites like Kandy in Sri Lanka

\section{Introduction}

Cordoned off its three sides by the Mahaweli River and the other side by a range of hills, Kandy is one of the most attractive cities in Sri Lanka. With such topography, Kandy had been best served as an old-time strategic home for the kings since its founding in the $14^{\text {th }}$ century [1]. The townscape of Kandy had been rapidly and dramatically changed since 1818 under the British rule [1] with its development as an administrative centre and the largest commercial hub of the central province. Colonial and postcolonial growths of Kandy have also attracted many alien settlers and businessmen. Integrated with more than 150,000 [2] multicultural inhabitants of various social classes, this small city is obviously the second busiest in Sri Lanka.

Escalation of any city as an administrative centre or a commercial hub is always attracting many clienteles and employees towards the city centre from neighbouring as well as outlying localities. As a heritage city, with the temple of tooth and many other cultural fascinations, Kandy attracts many local and foreign tourists throughout the year besides of the mass gatherings during the holy procession of the August season. And as a scholastic city, with the Sri Lanka's largest multidisciplinary university and many other higher educational institutions, Kandy attracts many academics and students from the whole country. Obviously, the magnitude of the mobility and accessibility needs in the Kandy city is far broader than what is expected from the census records of permanent inhabitants. Those needs are vigorously diverse and conflicting with the people of. various social clusters as known in many Asian cities [3].
As described by Goodwin [4], a private vehicle is considered as a convincing symbol of wealth, comfort, and development and so to do without a car is seen as synonymous with poverty. So the revenues through the plantation industry and tourism are escalating the glory of many social classes while developing an inevitable car dependent lifestyle in Kandy through many decades.

\section{From Public Transport to Cars}

Without any effective postcolonial rail infrastructure development around Kandy, the existing rail services are mainly focused on intercity travel while few trains are serving local communities. Hence the buses operated by the state and private bus owners did form the backbone of urban public transport services in this city. However, unreliability, overcrowding, boarding malpractices, discourteous crewmembers, and reckless driving have resulted in a decline in level of service, comfort, and the interest of using buses, desperately pulling out every able commuter into wheels. This situation is also enhanced by the Government's poor attention on improving public transport services. So the private automobile has increasingly dominated the travel patterns during the last three decades. In contrast, there had been a little

\footnotetext{
Eng. S. N. Bentotage, B. Sc. Eng. (Housh, M. Eng, MIESL C. Eng. profeticed iwenty years in industry and ncademia in assorted prostitoms attached to mamy reputed instliutions including Centml Engineering Cansuliancy Bureau. Asian Institure of Technolosy. Thol Engineering

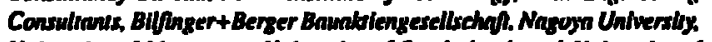
University of Moratuwa. Universily of Sundertuad, and Universily of Manchester. He was active in propasing Parting Incelligent Nerwork (PIN) for the Depantment for Trunspon (DST) based on the rity of Newcrstle upan Time in the UK.
} 
effort to build up the city with broader roads or bypass roads in this rolling terrain. This setting provides the obligatory surrounding for a city with congested roads so as we can experience in Kandy today.

\section{City Centre Parking Problem}

Growing numbers of vehicles entering into busy cities incessantly demand more parking spaces in the city centres creating traffic congestion. Having initiated in an era where the supply of parking for their customers was not essential, most businesses in Kandy are still running without any parking facility. Even with the legislations for the supply of parking, businessmen were smart enough to precede their developments with exceptionally few parking spaces. On-street free parking is legally permitted in many Sri Lankan roads. Additionally, on-street non-free parking based on the charges imposed by parking attendants is common in many cities. On the other hand, many Sri Lankans have an inapt attitude of "driving to the doors" rather than walking few minutes for their businesses after parking elsewhere. So the obvious gap between the demand and supply for "parking at doors" leaves many cars moving through additional kilometres in already congested roads. Even if they are moving for intended parking, these cars stress the city roads by decreasing mobility with the added congestion. The associated issues on mobility, environment, and safety have moved away from the promotion of on-street parking and instead many kinds of allotted parking areas are now open for car users in the city. The biggest ever car park that has a capacity of 900 cars was recently commissioned in the city centre of Kandy at a cost of Rs 600 million with funds provided by the Asian Development Bank [5].

\section{City centre Car parks in Developed Cities}

Transport policy makers had previously recognised the car parks as a viable solution for inner city parking needs in many developed cities so as they have recently mapped the same for Kandy. The allotted parking areas, while welcoming car users, remain as the most common solution for parking problems in many cities. There are many kinds of allotted parking areas open for car users in any city. Public and private business organisations offer charged parking facilities as well as their customer oriented free or discounted parking facilities in central business districts. Yet the increasing gap between demand and supply for parking leaves many cars on the roads seeking parking places. Many car users search for parking places en routing their destinations, mostly keeping them moving through additional kilometres in congested motorways. As elaborated by Hsiau and Yang [6], the choice of any parking place is associated with a loss that depends on the distance between the parking place and the destination. Apart from that, parking behaviour studies have proved that some vehicles spend as high as $95 \%$ of the trip cycle durations parked [7]. If the choice of parking cannot be met and as a result, queuing up of cars outside the many public and private parking lots is a common scene in most developed cities [Figure 1].

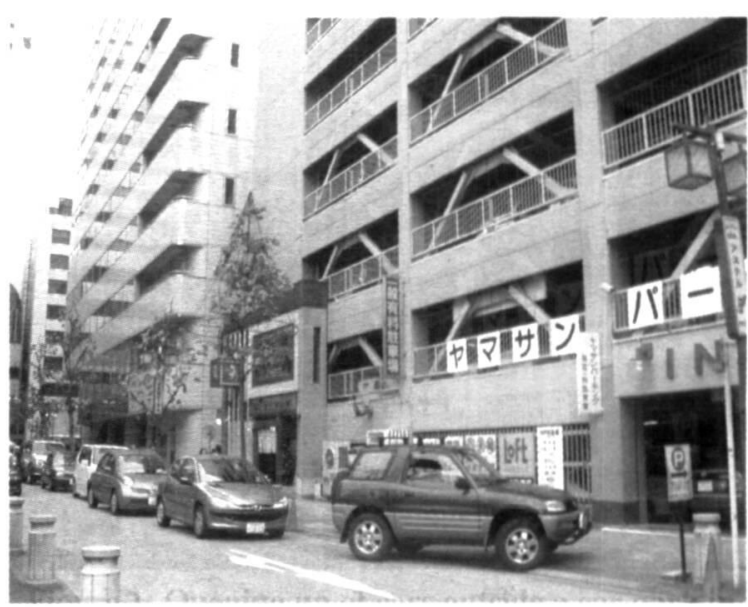

Figure 1: Queuing up of cars outside a car park in Sakae, Nagoya's CBD in Japan

No matter whether they are moving or waiting. queuing cars occupy road space in the city roads and decrease the mobility with added congestion [Figure 2]

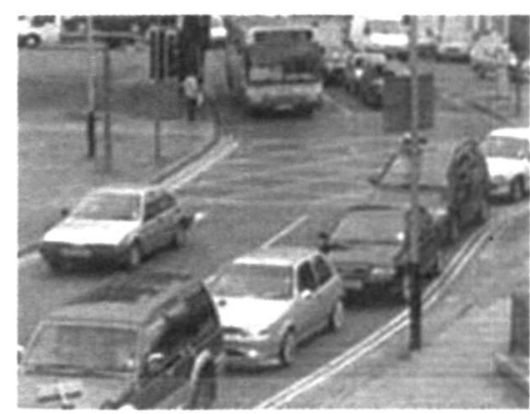

Figure 2: Motorists in Norwich (UK) face long queues for city centre parking. Source: BBC news, UK edition, Monday, 7 July 2003. 
In some cities, expensive technologies like CCTV surveillance are in operation to censor such queuing ups when disturbing the traffic flows [Figure 3]

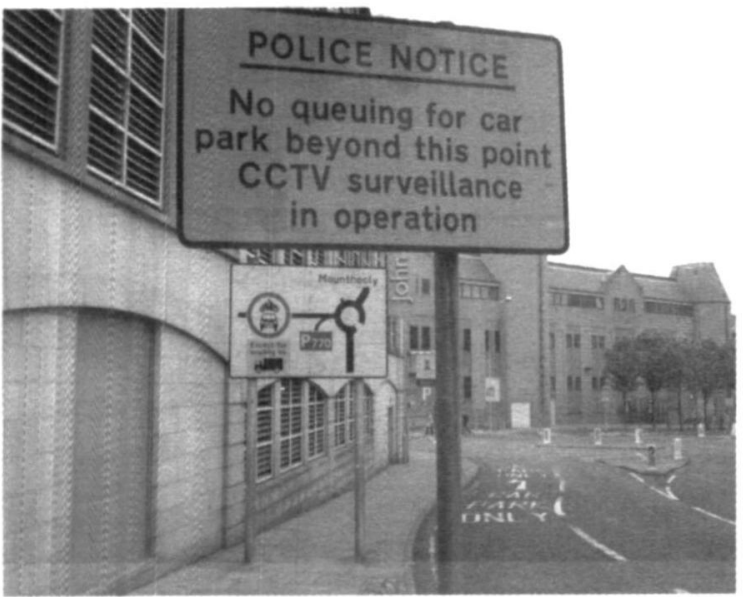

Figure 3: Police notice on censoring such queuing in Aberdeen, Scotland.

\section{Parking Management: An Expensive Solution?}

There were several studies on the extra rides associated with parking searches to divulge the waste in many developed cities. As revealed, rides linked to the unsuccessful attempts can make up as higher as $30 \%$ of the traffic of some main routes [8]. In some cities, such roaming may take up to $40 \%$ of the total riding times [9]. Hence the importance of controlling parking spaces has been defined and defended as an integral element for quite some time in developed cities [10]. A display of the available parking facilities for car users is widely adopted as a part of parking management in many developed cities. Such systems provide car users with available parking spaces at some designated parking lots as appeared within the cities and their outskirts in the form of Variable Message Signs (VMS) (also called Changeable Message Signs (CMS), Dynamic Message Signs (DMS), or Electronic Message Signs (EMS)) [Figure 4].

Incessantly supplied information on the networked parking lots are centrally collected before displaying in those VMS. The process mostly employs automatic surveillance systems to count the incoming and leaving vehicles while manual counts through the gate attendants are still in operation at some car parks. Such systems usually employ expensive software and hardware to ensure efficient and reliable information

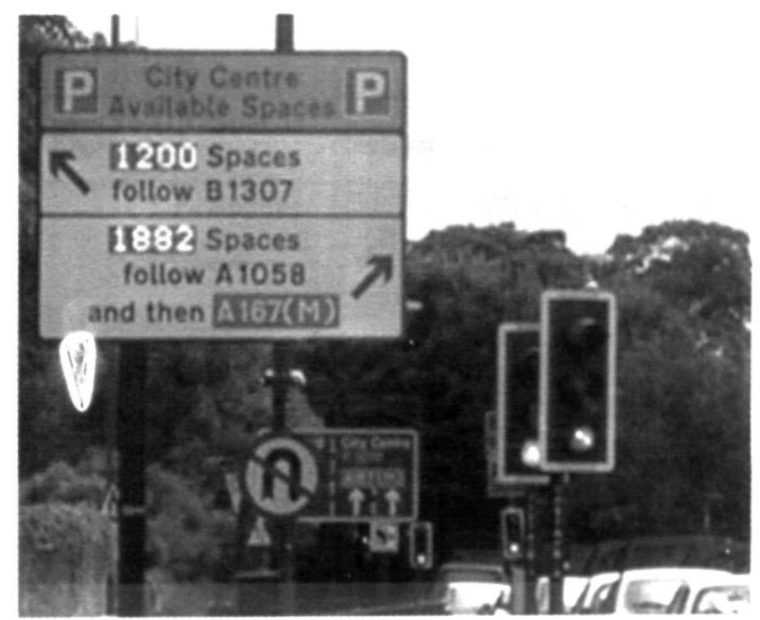

Figure 4: Variable message sign (VMS) to display the available spaces in Newcastle upon Tyne, England.

management. Even though the VMS has no obvious effect on reduction of travel time [11], they are useful as it helps car users to identify the best-suited vacant parking space.

Even with the VMS, car users can learn about the availability of parking only when they are on the way to their destination. That information could be too late for them to reorganise their trips in a situation of insufficient parking spaces. Also the information does not make any impact on traffic congestion, as the system does not discourage car users from entering into the cities. Having the initial choice of a car park, car users much more likely to consider revising their choices upon learning the actual conditions before progressing their trips [12], as they would be optimistic over the possibilities of finding a parking space amongst the many different allotted lots. Also, car users are unlikely to abandon or reroute their trips based on a display of no vacant parking spaces. Hence, intelligent parking networks where car users can receive information on the availability of parking based on telemetric resources to "arrange their trips before get into wheels" are under consideration in countries like Brazil too [10].

\section{Affordability of Advance Techniques}

Having thousands of highly dependable employees in production, sales, finance, insurance, petroleum, and service sectors on it, the automobile industry is ever strategising for auto booms in third world with the support of transport and industrial policymakers [13] 
Attesting the success of those strategies, the car ownership rate is rising very rapidly in all Asian cities [14]. With a relatively higher vehicle ownership of one vehicle per 63 persons in the region [3], and a record of registering around 600 new cars per week [15] in Sri Lanka, one cannot ascertain that the building up of car parks would clear the Kandy's narrow roads without pulling towards the chaos of the developed cities as evidenced. With plenty of buildings and lands with archaeological values, geographically constricted city like Kandy cannot be modified with multilane roads or flyovers. Conversely, as a third world country and with many other needy improvements in transport sector, one cannot justify on funding for VMS and information networks in Sri Lanka on any intelligent parking management.

Instead, the designers may obtain more sustainable solutions that have been proposed in the developed cities regarding the parking problem. Car parks always welcome cars and never discourage the cars entering into the cities and roaming for parking to stress the roads with congestion and pollution. So, any constructive proposal on sustainable roads must always stand on the idea of reducing car usage.

\section{Towards Sustainable Kandy City}

Having researched on the problems in congested cities, many authors have discussed on excessive car usage $[3,13,16]$. Promotion of public transport systems, congestion charging, promotion of nonmotorised transport modes, and area restrictions for cars are among the most discussed solutions. Therefore any future development proposals on the following would save the environment while improving the mobility in Kandy city.

Urban rail transport has received more attention as environmentally affable public transport systems in many busy cities [17, 18]. Without many corridors to expand the motorways, a system of urban rail would be a great option for Kandy and the coordinated feeder services could make it as an efficient method of transport [19]. With the current weedy situation of Sri Lanka Rail [20], one cannot expect much on rail infrastructure development unless any funded plan in action. Still it is possible to optimise the existing infrastructure by increasing the frequency of local trains from the suburbs like Kadugannawa,
Gampola and Matale. Introduction of new rail stops are necessary at densely populated strategic localities while improving the reliability and the quality of ride to convince for the switching commuters from wheels.

All kinds of intercity buses add extra congestion as they entered into the city and roaming for several hours before the departure. Those buses remain parked at roadsides and make extra trips on private businesses like fuelling or servicing if not returning empty. It is a common feature in Sri Lanka to have all bus terminals located in the city centres funnelling buses, passengers, and concomitant activities. Any development towards moving those bus terminals to city outskirts can abate the entrance of intercity buses into the city centre. It is worth to note the functioning of three separate bus terminals outside of the central business district (CBD) of Bangkok. Any development plan towards relocating bus terminals in Kandy would consider Peradeniya as an appropriate location for the buses bound for Colombo, Nuwara Eliya, Ratnapura etc. Alighting passengers can proceed to the city using either city buses operating in inner city routes or trains if the terminal is located next to the train station. Similarly, Katugastota and Tannekumbura could be the other locations for relocating bus terminals for the buses operating in the remaining routes. Construction of a road connecting Peradeniya, Katugastota, and Tannekumbura in the Mahaweli right bank would allow shuttle buses connecting those bus terminals. It is also necessary to proscribe the intercity buses entering into the inner city. Displaced bus terminals would automatically eradicate the need of larger bus terminals in the city centre while relocating many needy but disquieting businesses like unhygienic food stalls, service stations, and repair centres away.

Entrance of cars and other private vehicles into the city centre can be controlled with imposing an entrance fee based on either daily or monthly payment. As the entry corridors to the Kandy city are available through either bridges or saddles, it is easy to regulate the vehicle entries for the city limits. Developers can be encouraged on building outer city car parks, probably near the rail and bus terminals, for promoting park and ride. But promotion of park and ride is likely when level of public transport improved as an alternative for everyone [13]. The park and ride 
proposals must offer comfortable rides to pull back commuters from different social classes, especially the car owners, towards the public transport. Microbus service introduced through the congested roads in Bangkok had the similar objective [21]. With only seated passengers and without collapsible seats in aisles, those small buses are serving through busy wards of Bangkok for considerably higher fair. However the park and ride fee for a city like Kandy must be far lower than the intended city entry fees for cars to encourage the outer city parking. Priority for all public transport is equally important to gain the reliability among commuters by demarcating no car lanes at every potential avenues of the inner city.

Although bicycles are evenly considered in lowincome cities in India for the entire trip and in high-income cities in Japan as a feeder mode [3], it was not promoted in Kandy. Indeed there are avenues with negotiable slopes for bicycle rides within the Kandy city limits. But, it is important to consider the segregation of bicycles and motorised transport. Narrow sidewalks of the Kandy streets have conquered by street hawkers and display stalls of adjacent shops pulling out pedestrians to indiscipline walks on streets stressing drivers and retarding the mobility. There is a need of designating some roads as carfree zones for safe and free access of pedestrians while widening the other pedestrian walkways and making them free of street hawkers.

\section{Summary}

Cities like Kandy with geographical constrictions are always inflexible for chronological expansion of transport infrastructure while archaeologically important buildings and lands decisively stand for the right of ways of the existing roads. Shortages and the inferior quality of public transport and the boosts of personal wealth, on the other hand, pull out many commuters in to wheels in growing cities. The escalating numbers of cars always demand for road capacities and inner city parking despite of the unvarying infrastructure. Although parking spaces can entice car users for increased mobility for short spells, outcome at some larger cities are not that promising. The expensive management efforts on such cities are beyond the potential of a developing country. Without pursuing the same bloomer, the developing cities can learn the sustainable solutions that have been suggested for the developed cities. Development of the public transport as an alternative to everyone while restricting the car usage would be the best solution for a city. Developers are always willing to design projects based on their return rather than considering sustainable solutions. Under such circumstances, the legislators must be committed to promote and steer sustainable development plans rather than tallying tenure highlights.

\section{References}

1. Kandy City, http://www.kandycity.org/history.html, visited on 25 July 2005.

2. Wikipedia, the free encyclopedia, Kandy, http:// en.wikipedia.org/wiki/Kandy, visited on 25 July 2005.

3. Tiwari, Geetam, Towards A Sustainable Urban Transport System: Planning For Non-Motorized Vehicles In Cities, Transportation Research and Injury Prevention Program, Indian Institute of Technology, Delhi, http://www.unescap.org/ tctd/pubs/files/bulletin68_c.pdf, visited on 25 July 2005.

4. Goodwin, P. B., Traffic and Transport Psychology, Oxford: Pergamon, 1997.

5. KMC Car Park Subsidized with General Revenue, The Kandy News Online Edition, http:// www.kandynews.net/jul_aug_2005/index. shtml, July-August 2005, visited on 11 March 2006.

6. Hsiau, S and Yang, J, On Marcove-dependent parking problems, Joumal of Applied Probability, 41, No. 2, Jun 2004.

7. Valleley, M., Parking policy: towards an integrated perspective. Paper presented at eighth WCTR, Antwerp, July 1998.

8. Allen, P. A., Driver response to parking guidance and information systems, Traffic Engineering and Control 34, 1993.

9. Axhausen, K. W., Polak, J. W., Boltze, M. and Puzicha, J., Effectiveness of the parking guidance information system in Frankfurt am Main, Traffic Engineering and Control 35, 1994.

10. Vianna, M. M. B., da Silva Portugal, L., and Balassiano, R., Intelligent transportation systems and parking management: implementation potential in a Brazilian city, Cities, Vol 21, No. 2, Apr 2004.

11. Levinson, D. and Huo, H., Effectiveness of Variable Message Signs, Department of Civil Engineering, University of Minnesota, http:// 
www.ce.umn.edu / /evinson/Papers/ VMS.pdf\#search='variable\%20message\%20signs', visited on 25 July 2005.

12. Bonsall, P. \& Palmer, I., Modelling drivers' car parking behaviour using data from a travel choice simulator, Transportation Research Part C: Emerging Teclinologies, Vol 12, Issue 5, Oct 2004.

13. Monheim, Heiner, Better Mobility With Fewer Cars: A New Transport Policy For Europe, Geographical Paper No 165, Department of Applied Geography and Urban Planning at the University of Trier, Germany, January 2003.

14. Friedman, John, Cities Unbound: The Intercity Network in the Asia-Pacific Region, Management of Social Transformations, MOST, Discussion Paper Series - No. 23, http://www.unesco.org/most/ friedman. htm, visited on 25 July 2005.

15. Country Profile Sri Lanka, http:// store.eiu.com /index.asp?layout-show_sample\&product_id30000203 \& country_id=lk, visited on 25 July 2005.
16. Cooper, J., Ryley, T., and Smith, A., Contemporary Lifestyles and the Implications for Sustainable Development Policy: Lessons from the UK's most car dependent city, Belfast, Cities, Vol 18, Issue 2, April 2001.

17. Urban transport on the track, http://www.france. diplomatie.fr/label_france/ENGLISH/ DOSSIER/environnement/08.html, visited on 25 July 2005.

18. Rail Transport, Transport modes, EUROPA, http:/ /europa.eu.int/comm/research/transport/ tran_modes/rail_en.html, visited on 1 August 2005.

19. Study on Urban Transport Development-Final Report, World Bank, http://www.kas.de/ u pload/dokumente/megacities Urban_transport_development_asia-2000.pdf, visited on 1 August 2005.

20. No rail track repairs: Over 30,000 lives in danger, Sunday Observer 31 July 2005, http://www. sundayobserver.lk/, visited on 1 August 2005.

21. Busses in Bangkok, http:// www.thailandguru.com/ transport-buses-citybangkok.html, visited on 1 August 2005. 